\section{Natalizumab in pediatric multiple sclerosis patients}

\section{E. Ann Yeh and Bianca Weinstock-Guttman}

Abstract: Pediatric multiple sclerosis (MS) comprises $2-5 \%$ of all cases of MS. Although first-line disease-modifying therapy (DMT) including interferons and glatiramer acetate appear to be well tolerated in this population, recent work has suggested that a growing number of children suffer from disease which is resistant to treatment with these therapies. Natalizumab is a therapy which, although associated with a 1:1000 risk for progressive multifocal leukoencephalopathy (PML), has been shown to be well tolerated in the adult population and may lead to disease remission in adults with highly active disease. Reports of use of this therapy in the pediatric population with highly active disease have been published. This paper reviews current experience with the use of natalizumab in the pediatric MS population, with attention to potential risks and possible long-term outcomes in this population.

Keywords: adolescent, breakthrough disease, multiple sclerosis, natalizumab, pediatric, therapy, treatment

\section{Background and introduction}

Pediatric multiple sclerosis (MS) comprises $2-5 \%$ of all cases of MS. A growing body of data has suggested that US Food and Drug Administration (FDA)-approved medications used for the treatment of MS in adults, often referred as first-line disease modifying therapy (FL-DMT), including the interferons (IFNs) and glatiramer acetate (GA), are relatively well tolerated in the pediatric population [Ghezzi et al. 2009, 2005; Mikaeloff et al. 2008, 2001; Pohl et al. 2007, 2005; Banwell et al. 2006; Kornek et al. 2003].

However, the efficacy of these agents is often limited and may only result in a 30\% reduction in relapse rate in adults. Similarly, recent data have shown that many children with MS who are treated with FL-DMT do not tolerate or achieve adequate disease control on these therapies. Indeed, in a large retrospective study of children in the US, approximately $1 / 5$ of children on IFN and GA discontinued these therapies due to poor tolerance or compliance, and over $1 / 4$ changed therapies due to breakthrough disease [Yeh et al. 2009]. In children with breakthrough disease, chemotherapy and other newer agents including natalizumab, mitoxantrone, mycophenolate mofetil, rituximab and daclizupulse steroids/intravenous immunoglobulin (IVIG)/combination therapies with FL-DMT have been used with good results [Yeh et al. 2009; Makhani et al. 2009]. This paper reviews current experience with the use of natalizumab in the pediatric MS population, with particular attention paid to the potential risks and possible long-term outcomes in this population.

\section{Natalizumab: mechanism of action}

Natalizumab, a recombinant, humanized monoclonal antibody, binds to the $\alpha 4$ subunit of $\alpha 4 \beta 1$ (very late antigen- 4 [VLA-4]) and $\alpha 4 \beta 7$ integrins (adhesion molecules), hindering the interaction between VLA-4 and its counter-receptor, vascular endothelial adhesion molecule-1 (VCAM-1). Disruption of these molecular interactions antagonizes the leukocyte-endothelium adhesion processes necessary for efficient migration of leukocytes across the blood-brain barrier endothelium, reducing the recruitment of immune cells into sites of inflammation within the central nervous system (CNS) [Archelos et al. 1999]. This has been confirmed in animal models using acute experimental autoimmune encephalomyelitis (EAE) [Coisne et al. 2009; Yednock et al. 1992]. mab, and cyclophosphamide, in addition to
Ther Adv Neurol Disord

(2010) 3(5) 293-299

DOI: $10.1177 /$

1756285610381526

(C) The Author(s), 2010. Reprints and permissions:

http://www.sagepub.co.uk/ journalsPermissions.nav
Correspondence to: Bianca WeinstockGuttman, MD Pediatric Multiple Sclerosis and Demyelinating Disorders Center, Jacobs Neurological Institute, 100 High Street, Buffalo, NY 14203, USA bguttmanathejni.org

E. Ann Yeh, MD Pediatric Multiple Sclerosis and Demyelinating Disorders Center of the Jacobs Neurological Institute, Women and Children's Hospital of Buffalo, and Department of Neurology, State University of New York, Buffalo, NY, USA 


\section{Safety and efficacy}

Two pivotal, randomized, placebo-controlled phase III clinical trials showed that natalizumab was effective for the treatment of relapsing-remitting (RR) MS in adults (defined as individuals with RRMS between the age of 18 and 50) [Polman et al. 2006; Rudick et al. 2006]. In the AFFIRM trial [Polman et al. 2006], natalizumab treatment $(300 \mathrm{mg}$, IV infusion, once every 4 weeks) was compared with placebo. In the SENTINEL trial, the combination of natalizumab plus IFN- $\beta$-1a (natalizumab: $300 \mathrm{mg}$, intravenous infusion, once every 4 weeks; IFN- $\beta$-1a $30 \mu \mathrm{g}$, intramuscular injection, once weekly) was compared with placebo plus IFN- $\beta-1$ a [Rudick et al. 2006]. Both trials demonstrated the efficacy of natalizumab treatment in reducing relapse rate, visual loss, disease progression and occurrence of new magnetic resonance imaging (MRI) lesions in MS [Radue et al. 2010; Havrdova et al. 2009; Balcer et al. 2007; Miller et al. 2007].

Natalizumab appears to be effective for adults with highly active RRMS. Subgroup analysis of patients with highly active RRMS in the AFFIRM and SENTINEL trials showed a reduction in disability progression of $64 \%$, and a reduction in relapse rate by $81 \%$ in treatment naive patients with highly active disease and $58 \%$ and $76 \%$ in patients with highly active disease despite treatment with IFN- $\beta-1 \mathrm{a}$ [Hutchinson et al. 2009]. This finding has been reproduced in multicenter studies involving German-speaking and Danish populations [Putzki et al. 2010; Oturai et al. 2009].

A large proportion of adults with RRMS may be able to experience significant improvement in relapse rate on natalizumab: post hoc analysis of the AFFIRM data has shown that almost 2/3 $(64 \%)$ of patients treated with natalizumab versus $39 \%$ of those on placebo were free of clinical disease activity. Fifty-eight percent versus $14 \%$ were free of radiological disease activity and $37 \%$ versus $7 \%$ were free of combined activity over 2 years [Havrdova et al. 2009]. Conflicting evidence regarding rebound phenomena after discontinuation of natalizumab exists. Increased T2 lesion burden has been noted in a small study $(n=21)$ of patients after natalizumab cessation. Patients in this study were participants in the SENTINEL and AFFRIM trial. They were divided into two groups: one receiving placebo in the blinded portion of the study then switched to natalizumab in the open-label section of the study, and another receiving natalizumab while blinded then kept on natalizumab in the open-label section. Importantly, those patients who were more likely to develop increased T2 lesion burden after natalizumab cessation were on therapy for a shorter period of time and fell into the placebo-natalizumab group [Vellinga et al. 2008]. The significance of these findings is unclear.

By contrast, a small 14-month follow-up study of patients $(n=23)$ who discontinued natalizumab showed that decreased lymphocyte cell numbers and altered cell ratios returned to normal, and that the majority of patients were clinically stable after cessation of the therapy for the follow up period [Stüve et al. 2009]. Importantly, most of the patients in this study were treated with other immunomodulatory medications, primarily IFNs, after cessation of natalizumab. Thus, it is not clear whether the patients' clinical stability can be attributed to natalizumab or the immunomodulatory therapy initiated after natalizumab cessation.

In general, natalizumab is reported to be well tolerated in the adult population. Adverse events that were significantly more common in adults taking natalizumab compared with placebo in the AFFIRM trial were fatigue and allergic reactions. Infusion reactions, described as events occurring within two hours after the start of the infusion, were only slightly higher in natalizumab $(24 \%)$ versus placebo $(18 \%)(p=0.04)$ treated patients in the AFFIRM trial [Polman et al. 2006]. Recently, the FDA reported six individuals with clinically significant elevations in serum transaminases and bilirubin, four of which occurred after the first infusion, suggesting the need to monitor liver function tests in individuals being treated with natalizumab [Bezabeh et al. 2010].

\section{Pediatric use of natalizumab}

Large, controlled studies of the safety and efficacy of natalizumab have not been performed in the pediatric MS population. Two published manuscripts have described the use of natalizumab in a total of four children who had highly active disease or poor tolerance of first-line therapies [Borriello et al. 2009; Huppke et al. 2008]. The first, a case report, described a 12-year-old girl experiencing clinical relapses and ongoing disease activity on MRI 
(gadolinium-enhanced lesions) despite treatment with IFN for 10.5 months. Treatment with natalizumab $300 \mathrm{mg} /$ day resulted in cessation of MRI and clinical evidence of disease activity for the 11-month follow-up period described [Borriello et al. 2009].

In the second case series, dosing was 3-5 mg/ $\mathrm{kg} /$ dose/month IV. Again, relapses persisted despite treatment with IFN and GA in all children prior to introduction of natalizumab. Use of natalizumab resulted in the cessation of MRI and clinical relapses in all three children after follow up for 15, 16, and 24 months. The medication was well tolerated by these children [Huppke et al. 2008].

Our group recently described 24 pediatric MS patients treated with natalizumab as part of the US Network of Pediatric MS Centers. All children received a dose of natalizumab $300 \mathrm{mg} /$ month, following the standard adult treatment protocol. Most of the patients were adolescents, with an average age at time of treatment initiation of 14 years ( $\mathrm{SD} \pm 2.3$ years) [Yeh et al. 2010]. The majority of these children (75\%) received the therapy as a fourth or fifth agent, suggesting that most children receiving this therapy had failed multiple FL-DMTs [Yeh et al. 2009]. The medication was relatively well tolerated. Twenty patients $(83 \%)$ had a very good response, remaining stable with respect to $M R I$ and clinical parameters for the extent of the follow-up period (average 1.5 years) [Yeh et al. 2010]. However, four patients discontinued therapy due to poor tolerance and/or hypersensitivity reaction.

Dosing in the pediatric population has not been established, as can be seen from the varying approaches in the published literature $(3-5 \mathrm{mg}$ / $\mathrm{kg}$ /dose versus $300 \mathrm{mg} /$ dose). It is possible that doses as low as $3 \mathrm{mg} / \mathrm{kg} /$ dose may be effective: a study of its use in Crohn's disease in the pediatric population suggested a mean alpha-4 integrin receptor saturation of $93 \%$ at 2 hours and $<40 \%$ at 4 weeks after the first and third infusions at a dose of $3 \mathrm{mg} / \mathrm{kg} /$ dose [Hyams et al. 2007].

\section{Antinatalizumab antibodies, efficacy and hypersensitivity reactions}

Antinatalizumab antibodies appear to have an influence on medication efficacy. These antibodies were seen transiently in 3\% and persistently in $6 \%$ of the SENTINEL and AFFIRM patients [Calabresi et al. 2007]. Patients with persistently positive antinatalizumab antibody titers have been shown to experience increased disability progression, relapse rate, and MRI lesion formation compared with antibody negative patients [Calabresi et al. 2007; Polman et al. 2006]. One child in the US series discontinued therapy due to a hypersensitivity reaction associated with antibodies to natalizumab [Yeh et al. 2010]. Hypersensitivity reactions, described as hypersensitivity, allergic reaction, analyalytic/ anaphylactoid reaction, urticaria, allergic dermatitis, or hives, were reported in $4 \%$ of patients enrolled in the AFFIRM trial frequently associated with the presence of antinatalizumab antibodies [Polman et al. 2006].

A delayed (2-3 days after treatment) serumsickness type reaction (type III) has also been described in adult patients, and may be associated with antinatalizumab antibodies [Hellwig et al. 2008; Krumbholz et al. 2007]. One study suggests the incidence of this type of reaction may be as high as $10 \%$ (4/40 patients) [Hellwig et al. 2008]. This type of reaction may be treated with the use of steroids and reduction of the infusion rate, although discontinuation of natalizumab should take place with antibody-positive patients [Hellwig et al. 2008; Krumbholz et al. 2007]. This type of hypersensitivity reaction has not been described in the pediatric population yet.

\section{Progressive multifocal leukoencephalopathy and other significant adverse effects}

Progressive multifocal leukoencephalopathy

Important long-term risks have been described in relation to the use of natalizumab in the adult population with MS. The first three reports of cases of progressive multifocal leukoencephalopathy (PML) in relation to treatment with natalizumab were published in 2005 [Kleinschmidt-DeMasters and Tyler, 2005; Langer-Gould et al. 2005; VanAssche et al. 2005]. PML is a rare, often fatal central nervous system infection caused by the JC polyomavirus. These reports prompted its withdrawal from the US market by the FDA that year. After extensive review, including evaluation of over 3000 patients who had been treated with the drug, the risk of development of PML was found to be $1: 1000$ [Yousry et al. 2006].

Owing to the associated risk of PML, an individualized risk/benefit assessment is necessary prior 
to initiation of therapy, and a high level of clinical vigilance must be maintained during the therapy. In March 2006, the Peripheral and Central Nervous Systems Drugs Advisory Committee of the FDA approved making natalizumab available under a surveillance plan (TOUCH program). This program includes the following features: (1) the drug can only be prescribed, distributed and infused by prescribers, infusion centers, and pharmacies registered with the program; (2) natalizumab can be administered only to patients enrolled in the program; (3) MRI scans must be done prior to initiation of the therapy; (4) patients on natalizumab must be evaluated at 3 and 6 months after the first infusion and every 6 months thereafter, with regular reports to the manufacturer (Biogen Idec).

Initial reports of PML associated with natalizumab suggested that patients on a concomitant therapy could be at higher risk of developing this complication. However, as experience with the drug has grown, it has become clear that this risk is not limited to these individuals. In 2009, a case report of an individual patient on natalizumab monotherapy who developed PML was published [Linda et al. 2009], and by late 2009 , a total of 28 cases had been confirmed, some of which were associated with monotherapy. Eight of these cases were fatal [Clifford et al. 2010]. It is now clear that risk increases with length of treatment: average time on therapy in these patients was 25 months (range 6-80 months) [Clifford et al. 2010].

Treatment for PML in natalizumab-associated cases includes the use of plasma exchange and immunoadsorption to eliminate the presence of the drug and restore immune effector function [Khatri et al. 2009]. Unfortunately, this is often followed by immune reconstitution inflammatory syndrome (IRIS), which leads to widespread CNS inflammation, often treated with pulse steroids [Clifford et al. 2010; Wenning et al. 2009]. At this point, screening of urine or serum for JC virus does not appear to be helpful in the early detection of PML in natalizumab-treated patients or risk stratification of these patients, as subclinical reactivation in JC virus may occur frequently in patients on natalizumab [Chen et al. 2009].

There have been no cases of natalizumab-related PML reported in the pediatric population with MS. Importantly, studies have shown that fewer than $25 \%$ of immunocompetent children have been infected with JC virus as opposed to half or two thirds of adults. The number increases with age: fewer than $15 \%$ of children under the age of 10 have been infected with JC virus [Polo et al. 2004; Knowles et al. 2003]. As PML is the result of reactivation of a primary, usually asymptomatic infection with the JC virus, children may be at lower risk for this condition, as long as JC virus infection has not yet occurred. Epidemiologic studies suggest this may be true: only one of 79 consecutive confirmed cases of PML in a Norwegian county was under the age of 10 [Stoner et al. 1988].

Few reports of PML in the pediatric population exist; it has been described in relation to primary immunodeficiency syndromes, such as Wiskott-Aldrich syndrome [Katz et al. 1994] and hyperimmunoglobulin $\mathrm{E}$ recurrent infection syndrome [Angelini et al. 2001] as well as in acquired immunodeficiency syndromes, such as in HIV-infected children [Liptai et al. 2007; Nuttall et al. 2004; Singer et al. 1993; Berger et al. 1992]. In most of these cases, the children were 12 years of age or older, although it has also been described in 5-, 10-, and 11-year-old children with HIV and inherited immunodeficiency syndromes [Katz et al. 1994; Berger et al. 1992]. Taken together, this literature suggests that PML does occur in the pediatric population, but possibly at lower rates than in the adult population. Whether children on immunosuppressive therapies truly have lower risk of developing PML, however, remains to be seen in future studies.

\section{Other serious outcomes}

Although the AFFIRM trial reported a similar incidence of cancer in the control and treatment groups ( 1 versus 5 patients, $<1 \%$ in both groups) [Polman et al. 2006], more recently, reports of melanoma and primary CNS lymphoma have been described in relation to natalizumab [Schweikert et al. 2009]. Longitudinal studies are needed to clarify the association of these diseases with natalizumab use.

There have been no reports of cancer in pediatric patients treated with natalizumab. The rate of primary central nervous system lymphoma is $0.02 /$ 100,000 in childhood, with a 15 -fold increase in risk in the $30 \mathrm{~s}$, to a 100 -fold increase in risk in the $70 \mathrm{~s}$ [Schweikert et al. 2009]. It is unknown how immunosuppression changes this risk. 
However, as immunosuppression may be a predisposing condition leading to the development of primary CNS lymphoma, vigilance in the pediatric population receiving natalizumab is necessary.

\section{Conclusion}

Natalizumab appears to be well tolerated in the pediatric MS population. Its use thus far has been limited to children with highly active MS who have experienced breakthrough disease despite the use of FL-DMTs. Dosing of natalizu$\mathrm{mab}$ in the pediatric population has not been established yet. It appears to reduce relapse rate in case series with limited follow up. The optimal duration of treatment with natalizumab in this population has not been established; the risks and benefits of prolonged treatment must be weighed given the known increased risk of development of PML in the adult population which is associated with longer duration of therapy. Use of natalizumab in this population should be approached with caution as development of serious side effects reported in the adult population, including PML and cancer may be anticipated as experience with the medication in pediatric MS patients grows.

\section{Funding}

The National MS Society provided funding for Pediatric MS Center of Excellence of the JNI.

\section{Conflict of interest statement}

The authors report no conflicts of interest. Dr Yeh has received financial support for research activities from the National Institutes of Health, the Jog for the Jake Foundation and the Children's Guild Foundation. National MS Society provided financial support for the Pediatric MS Center of Excellence of the JNI. Dr Bianca Weinstock-Guttman has received personal compensation from Biogen Idec, Teva Neuroscience EMD Serono, Pfizer, Novartis, Sanofi and Questcor Pharmaceuticals for consulting, speaking fees and advisory boards and received financial support for research activities from Biogen Idec, Teva Neuroscience, Questcor Pharmaceuticals, EMD Serono, Aspreva, Novartis, Sanofi Aventis, NMSS, NIH, DOD and Jog for the Jake Foundation.

\section{References}

Angelini, L., Pietrogrande, M.C., Delle Piane, M.R., Zibordi, F., Cinque, P., Maccagnano, C. et al. (2001) Progressive multifocal leukoencephalopathy in a child with hyperimmunoglobulin $\mathrm{E}$ recurrent infection syndrome and review of the literature. Neuropediatrics 32: 250-255.

Archelos, J., Pervitali, S. and Hartung, H. (1999) The role of integrins in immune-mediated diseases of the nervous system. Trends Neurosci 22: 30-38.

Balcer, L.J., Galetta, S.L., Calabresi, P.A., Confavreux, C., Giovannoni, G., Havrdova, E. et al. (2007) Natalizumab reduces visual loss in patients with relapsing multiple sclerosis. Neurology 68: 1299-1304.

Banwell, B., Reder, A.T., Krupp, L., Tenembaum, S., Eraksoy, M., Alexey, B. et al. (2006) Safety and tolerability of interferon beta-1b in pediatric multiple sclerosis. Neurology 66: 472-476.

Berger, J.R., Scott, G., Albrecht, J., Belman, A.L., Tornatore, C. and Major, E.O. (1992) Progressive multifocal leukoencephalopathy in HIV-1-infected children. AIDS 6: 837-841.

Bezabeh, S., Flowers, C.M., Kortepeter, C. and Avigan, M. (2010) Clinically significant liver injury in patients treated with natalizumab. Aliment Pharmacol Ther 31: 1028-1035.

Borriello, G., Prosperini, L., Luchetti, A. and Pozzilli, C. (2009) Natalizumab treatment in pediatric multiple sclerosis: a case report. Eur $\mathcal{F}$ Paediatr Neurol 13: $67-71$.

Calabresi, P.A., Giovannoni, G., Confavreux, C., Galetta, S.L., Havrdova, E., Hutchinson, M. et al. (2007) The incidence and significance of antinatalizumab antibodies: results from AFFIRM and SENTINEL. Neurology 69: 1391-1403.

Chen, Y., Bord, E., Tompkins, T., Miller, J., Tan, C.S., Kinkel, R.P. et al. (2009) Asymptomatic reactivation of JC virus in patients treated with natalizumab. $N$ Engl f Med 361: 1067-1074.

Clifford, D.B., De Luca, A., Simpson, D.M., Arendt, G., Giovannoni, G. and Nath, A. (2010) Natalizumabassociated progressive multifocal leukoencephalopathy in patients with multiple sclerosis: lessons from 28 cases. Lancet Neurol 9: 438-446.

Coisne, C., Mao, W. and Engelhardt, B. (2009) Cutting edge: natalizumab blocks adhesion but not initial contact of human $\mathrm{T}$ cells to the blood-brain barrier in vivo in an animal model of multiple sclerosis. f Immunol 182: 5909-5913.

Ghezzi, A., Amato, M.P., Annovazzi, P., Capobianco, M., Gallo, P., La Mantia, L. et al. (2009) Long-term results of immunomodulatory treatment in children and adolescents with multiple sclerosis: the Italian experience. Neurol Sci 30: 193-199.

Ghezzi, A., Amato, M.P., Capobianco, M., Gallo, P., Marrosu, G., Martinelli, V. et al. (2005) Diseasemodifying drugs in childhood-juvenile multiple sclerosis: results of an Italian co-operative study. Mult Scler 11: 420-424.

Havrdova, E., Galetta, S., Hutchinson, M., Stefoski, D., Bates, D., Polman, C.H. et al. (2009) Effect of 
natalizumab on clinical and radiological disease activity in multiple sclerosis: a retrospective analysis of the Natalizumab Safety and Efficacy in RelapsingRemitting Multiple Sclerosis (AFFIRM) study. Lancet Neurol 8: 254-260.

Hellwig, K., Schimrigk, S., Fischer, M., Haghikia, A., Muller, T., Chan, A. et al. (2008) Allergic and nonallergic delayed infusion reactions during natalizumab therapy. Arch Neurol 65: 656-658.

Huppke, P., Stark, W., Zurcher, C., Huppke, B., Bruck, W. and Gartner, J. (2008) Natalizumab use in pediatric multiple sclerosis. Arch Neurol 65: 1655-1658.

Hutchinson, M., Kappos, L., Calabresi, P.A., Confavreux, C., Giovannoni, G., Galetta, S.L. et al. (2009) The efficacy of natalizumab in patients with relapsing multiple sclerosis: subgroup analyses of AFFIRM and SENTINEL. $\mathcal{F}$ Neurol 256: 405-415.

Hyams, J.S., Wilson, D.C., Thomas, A., Heuschkel, R., Mitton, S., Mitchell, B. et al. (2007) Natalizumab therapy for moderate to severe Crohn disease in adolescents. F Pediatr Gastroenterol Nutr 44: 185-191.

Katz, D.A., Berger, J.R., Hamilton, B., Major, E.O. and Post, M.J. (1994) Progressive multifocal leukoencephalopathy complicating Wiskott-Aldrich syndrome. Report of a case and review of the literature of progressive multifocal leukoencephalopathy with other inherited immunodeficiency states. Arch Neurol 51: 422-426.

Khatri, B.O., Man, S., Giovannoni, G., Koo, A.P., Lee, J.C., Tucky, B. et al. (2009) Effect of plasma exchange in accelerating natalizumab clearance and restoring leukocyte function. Neurology 72: 402-409.

Kleinschmidt-DeMasters, B. and Tyler, K. (2005) Progressive multifocal leukoencphalopathy complicating treatment with natalizumab and interferon beta-1a for multiple sclerosis. $N$ Engl f Med 353: 369-374.

Knowles, W.A., Pipkin, P., Andrews, N., Vyse, A., Minor, P., Brown, D.W. et al. (2003) Population-based study of antibody to the human polyomaviruses BKV and JCV and the simian polyomavirus SV40. $7 \mathrm{Med}$ Virol 71: 115-123.

Kornek, B., Bernert, G., Balassy, C., Geldner, J., Prayer, D. and Feucht, M. (2003) Glatiramer acetate treatment in patients with childhood and juvenile onset multiple sclerosis. Neuropediatrics 34: 120-126.

Krumbholz, M., Pellkofer, H., Gold, R., Hoffmann, L.A., Hohlfeld, R. and Kumpfel, T. (2007) Delayed allergic reaction to natalizumab associated with early formation of neutralizing antibodies. Arch Neurol 64: 1331-1333.

Langer-Gould, A., Atlas, S., Green, A.J., Bollen, A.W. and Pelletier, D. (2005) Progressive multifocal encephalopathy in a patient treated with natalizumab. $N$ Engl f Med 353: 375-381.

Linda, H., von Heijne, A., Major, E.O., Ryschkewitsch, C., Berg, J., Olsson, T. et al. (2009)

Progressive multifocal leukoencephalopathy after natalizumab monotherapy. $N$ Engl $\mathcal{F}$ Med 361: 1081-1087.

Liptai, Z., Papp, E., Barsi, P., Mihaly, I., Szalai, E., Csomor, J. et al. (2007) Progressive multifocal leukoencephalopathy in an HIV-infected child. Neuropediatrics 38: 32-35.

Makhani, N., Gorman, M.P., Branson, H.M., Stazzone, L., Banwell, B.L. and Chitnis, T. (2009) Cyclophosphamide therapy in pediatric multiple sclerosis. Neurology 72: 2076-2082.

Mikaeloff, Y., Caridade, G., Tardieu, M. and Suissa, S. (2008) Effectiveness of early beta interferon on the first attack after confirmed multiple sclerosis: a comparative cohort study. Eur $\mathcal{F}$ Paediatr Neurol 12: 205-209.

Mikaeloff, Y., Moreau, T., Debouverie, M., Pelletier, J., Lebrun, C., Gout, O. et al. (2001) Interferon-beta treatment in patients with childhoodonset multiple sclerosis. F Pediatr 139: 443-446.

Miller, D.H., Soon, D., Fernando, K.T., MacManus, D.G., Barker, G.J., Yousry, T.A. et al. (2007) MRI outcomes in a placebo-controlled trial of natalizumab in relapsing MS. Neurology 68: 1390-1401.

Nuttall, J.J., Wilmshurst, J.M., Ndondo, A.P., Yeats, J., Corcoran, C., Hussey, G.D. et al. (2004) Progressive multifocal leukoencephalopathy after initiation of highly active antiretroviral therapy in a child with advanced human immunodeficiency virus infection: a case of immune reconstitution inflammatory syndrome. Pediatr Infect Dis $\mathcal{F} 23$ : 683-685.

Oturai, A.B., Koch-Henriksen, N., Petersen, T., Jensen, P.E., Sellebjerg, F. and Sorensen, P.S. (2009) Efficacy of natalizumab in multiple sclerosis patients with high disease activity: a Danish nationwide study. Eur F Neurol 16: 420-423.

Pohl, D., Rostasy, K., Gartner, J. and Hanefeld, F. (2005) Treatment of early onset multiple sclerosis with subcutaneous interferon beta-1a. Neurology 64: 888-890.

Pohl, D., Waubant, E., Banwell, B., Chabas, D., Chitnis, T., Weinstock-Guttman, B. et al. (2007) Treatment of pediatric multiple sclerosis and variants. Neurology 68(16 Suppl 2): S54-S65.

Polman, C.H., O’Connor, P.W., Havrdova, E., Hutchinson, M., Kappos, L., Miller, D.H. et al. (2006) A randomized, placebo-controlled trial of natalizumab for relapsing multiple sclerosis. $N \mathrm{Engl} \mathcal{F} \mathrm{Med}$ 354: 899-910.

Polo, C., Perez, J.L., Mielnichuck, A., Fedele, C.G., Niubo, J. and Tenorio, A. (2004) Prevalence and patterns of polyomavirus urinary excretion in immunocompetent adults and children. Clin Microbiol Infect 10: 640-644.

Putzki, N., Yaldizli, O., Maurer, M., Cursiefen, S., Kuckert, S., Klawe, C. et al. (2010) Efficacy of natalizumab in second line therapy of relapsing-remitting multiple sclerosis: results from a 
multi-center study in German speaking countries. Eur f Neurol 17: 31-37.

Radue, E.W., Stuart, W.H., Calabresi, P.A., Confavreux, C., Galetta, S.L., Rudick, R.A. et al. (2010) Natalizumab plus interferon beta-1a reduces lesion formation in relapsing multiple sclerosis. f Neurol Sci 292: 28-35.

Rudick, R.A., Stuart, W.H., Calabresi, P.A., Confavreux, C., Galetta, S.L., Radue, E.W. et al. (2006) Natalizumab plus interferon beta-1a for relapsing multiple sclerosis. $N$ Engl f Med 354: 911-923.

Schweikert, A., Kremer, M., Ringel, F., Liebig, T., Duyster, J., Stüve, O. et al. (2009) Primary central nervous system lymphoma in a patient treated with natalizumab. Ann Neurol 66: 403-406.

Singer, C., Berger, J.R., Bowen, B.C., Bruce, J.H. and Weiner, W.J. (1993) Akinetic-rigid syndrome in a 13-year-old girl with HIV-related progressive multifocal leukoencephalopathy. Mov Disord 8: 113-116.

Stoner, G.L., Walker, D.L. and Webster, H.D. (1988) Age distribution of progressive multifocal leukoencephalopathy. Acta Neurol Scand 78: 307-312.

Stüve, O., Cravens, P.D., Frohman, E.M., Phillips, J.T., Remington, G.M., von Geldern, G. et al. (2009) Immunologic, clinical, and radiologic status 14 months after cessation of natalizumab therapy. Neurology 72: 396-401.

VanAssche, G., Ranst, M.V., Sciot, R., Dubois, B., Vermeire, S., Noman, M. et al. (2005) Progressive multifocal leukoencephalopathy after natalizumab therapy for Crohn's disease. $N$ Engl f Med 353: 362-368.

Vellinga, M.M., Castelijns, J.A., Barkhof, F., Uitdehaag, B.M. and Polman, C.H. (2008)

Postwithdrawal rebound increase in T2 lesional activity in natalizumab-treated MS patients. Neurology 70: 1150-1151.

Wenning, W., Haghikia, A., Laubenberger, J., Clifford, D.B., Behrens, P.F., Chan, A. et al. (2009) Treatment of progressive multifocal leukoencephalopathy associated with natalizumab. $N$ Engl F Med 361: 1075-1080.

Yednock, T.A., Cannon, C., Fritz, L.C., SanchezMadrid, F., Steinman, L. and Karin, N. (1992) Prevention of experimental autoimmune encephalomyelitis by antibodies against alpha 4 beta 1 integrin. Nature 356: 63-66.

Yeh, E., Krupp, L., Kuntz, N., Ness, J., Chabas-Chanzon, D., Chitnis, T. et al. (2010) Use of natalizumab in pediatric MS patients: a pediatric network experience. Neurology 74(9 Suppl 2): A100

Yeh, E., Krupp, L., Ness, J., Chabas, D., Belman, A., Waubant, E. et al. (2009) Breakthrough disease in pediatric MS patients: a pediatric network experience. Annual Meeting of the American Academy of Neurology, Seattle, WA.

Yousry, T.A., Major, E.O., Ryschkewitsch, C., Fahle, G., Fischer, S., Hou, J. et al. (2006) Evaluation of patients treated with natalizumab for progressive multifocal leukoencephalopathy. $N$ Engl F Med 354: 924-933.
Visit SAGE journals online http://tan.sagepub.com

(3SAGEJOURNALS 